\title{
Seafloor noise ensemble from vessel manoeuvre in the central North Sea
}

5 Abstract

Anthropogenic noise, e.g., shipping noise, are usually unavoidable and radiate over a certain area, e.g., $10 \mathrm{~km}$ depending on the noise source level and acoustic propagation channel, which might affect seabed acoustic engineering as well as species' communication, behaviour, fitness and consequently their survival. Therefore, better understanding of these noise sources allows better prediction of performance of seafloor acoustic research, engineering, and biological environment. Measurements from a hydrophone system mounted on the seafloor in the central North Sea permit comparisons between temporal and spectral seafloor noise as a vessel transits nearby. The measured data indicates that the peak energy in the power spectral density (PSD) of seafloor noise is dominated by that of multiple vessel tonal noise. The tidal level has a strong negative correlation with the seafloor noise variance, and the vessel to hydrophone angle has a modest negative correlation with both the noise variance and kurtosis, particularly within a certain distance (6.6 km at depth $150 \mathrm{~m}$ here). As the vessel approaches, the seafloor noise is sensitive to the noise radiated from the vessel manoeuvre dominated at frequencies 400-900 Hz. Further, as the vessel speed increases from 2 knots to 15 knots, the vessel tonal increases the PSD by 10-20 dB at multiple narrow frequency bands $(770$ and $850 \mathrm{~Hz})$. Results reported here advance the knowledge of seafloor acoustic sensitivity to nearby transit vessels.

6 Keywords: underwater acoustics, seafloor, tide, wind, shipping noise, vessel 7 manoeuvre.

\section{Introduction}

Underwater research and engineering often involve underwater acoustic operations close to the seafloor, such as seafloor mapping, sub-sea gas leakage monitoring, tracking and navigation of underwater vehicles or divers, detection of submariners, and underwater acoustic communications [1, 2, 3, 4, 5, 6, 7, 8, 9, 10, 11, 12, 13, 14. Acoustic operations benefit from a high signal-to-noise ratio (SNR), which may be compromised by noise in the ocean, e.g., from transit vessel noise and sea surface noise. These noise sources are usually unavoidable [15, 16, 17, and may affect the acoustic operations as well as the biological environment [18, 19, 20]. Vessel noise varies greatly from vessel to vessel [21, while research vessel itself is usually the noise source for underwater acoustic research, e.g., marine carbon capture and storage 22, 23, 24. Here we investigate the ensemble of seafloor noise in the presence of a research vessel transiting within $<10 \mathrm{~km}$ associated with natural environment characteristics.

Underwater ambient noise up to several $\mathrm{kHz}$ is a combination of turbulence, seismic, biological, surface wind and waves, precipitation, and anthropogenic (i.e., traffic) components 25, 26, 27]. Oceanic turbulence flow noise tends to dominate at low frequencies, e.g., less than $10 \mathrm{~Hz}$, while ship traffic/transit noise is usually concentrated between $10 \mathrm{~Hz}$ and $1 \mathrm{kHz}$ [28, 29], and sea surface noise may be observed from $100 \mathrm{~Hz}$ to $100 \mathrm{kHz}$ 30, 31. The anthropogenic noise and sea surface associated noise play significant role in ambient noise levels [25, 26, 32, 17, 15, 16, 33, 34, 31, 35, 36, and are time and space varying quantities. It is rather too simplistic to single out anthropogenic noise and sea surface noise as well as precipitation as non-stationary. The wave noise increases as the wind speed increases, precipitation noise varies with type (rain, drizzle, snow), and the traffic noise increases with the number of vessels, speed, size, engine revolutions per minute (RPM) increases and distance reduces. Traffic noise also varies with

\footnotetext{
*Corresponding author: Jianghui Li
} 
vessel type, propeller technologies (such as ducts, boss cap fins, blade shape), engine type, machinery mounts, hull cleanliness, propeller maintenance, and propeller depth.

In recent years there has been a rejuvenation of interest in underwater noise from vessels, based on the potential impact of this noise on marine life, involving modelling [37, 38, and field experiments 33, 32, 34, 39. Despite the advances in computational modelling, there remains a level of complexity associated with the noise mechanisms which means that field measurements continue to be indispensable. While some field experiments were made close to the sea surface or the noise sources [25, 40, 17, 41, 34], and the levels may not be representative of seafloor noise values and may not be capable of providing precise ambient noise information and supporting the seafloor acoustic operations with sufficient SNR, owing to the complex underwater acoustic channels [4]. Some of previous studies on shipping noise/ambient noise measurement were considered mooring in the water column rather than near surface [21, 42, 43. The largest bottom mounted measurement set on vessels to date may be the port of Vancouver Enhancing Cetacean Habitat and Observation (ECHO) program underwater listening station (2015-2018) with over 5000 vessel measurements [44, 45, while noise measurement focused on a single transit vessel in or near a port can easily be affected by other anthropogenic noise from the shore or traffic vessels. Also over $430 \mathrm{~TB}$ of bottom mounted hydrophone data and supporting Automatic Identification System (AIS) data have been collected by Ocean Networks Canada and Scripps Institution of Oceanography. Work [46, 47] has been done to provide guidance on best practice for in-situ measurement of underwater sound, e.g., shipping noise and ambient noise. Accurate characterization of changes in seafloor noise are confounded by variability over a wide range of temporal and spatial scales [26, 48, 46, involving the vessel speed, direction, distance, the sea surface wind speed, precipitation and bottom type. Therefore, all these parameters should be taken into account when we conduct the noise characterization and estimate the acoustic impact near the seafloor.

The spectral content of shipping noise depends on many factors including the size of the vessel, its engine type, prevailing sea state, etc [49]. Shipping related noise, including machinery noise and noise from the wake of the vessel. The machinery noise contains multiple sub-noise sources, e.g., vessel's service generator, main engine firing rate, and blade rate harmonics due to propeller cavitation [17, 50. Generator noise can be a main contributor of the machinery vibration noise at low vessel speeds, while propeller cavitation can be the main contributor at high vessel speeds [17, 3]. However, shipping noise is usually considered as noise source from the vessel itself [49, ignoring the wave breaking noise generated from the vessel hull (bow, stern, and body). Studies on the propeller-shaft-hull acoustic radiation and the three-dimensional sono-elasticity method about the acoustic radiation of a ship have been active in the last decades [51, 52. To date, there are few civilian analyses of the directivity of shipping noise contributing to the seafloor noise.

Many semi-empirical wind speed related underwater ambient noise have been presented [25] both in spectra and levels, but few experimental research on such topic have been conducted. Some of these experiments consisted of wind related underwater ambient noise measurements, but most of these measured levels are close to the sea surface. The wind speed is highly correlated with the wave height at frequencies above $200 \mathrm{~Hz}[53$ and can be the principal contributor to the ambient noise in the ocean at frequencies above $2 \mathrm{kHz}$ [54]. Also, the raindrops splashing on a water surface and produce distinctive sound underwater [55], and the tidal level affects the acoustic propagation in the underwater channel.

Here we measure the seafloor noise as a research vessel transits nearby $(<10 \mathrm{~km})$ in the central North Sea. During the transit, we recorded the tidal level, wind speed/direction, vessel speed/direction, and vessel to hydrophone distance $\left(d_{\mathrm{vh}}\right)$ and angle $\left(\theta_{\mathrm{vh}}\right)$. By comparing these recorded parameters and the measured noise, we show that the tidal level has a strong negative correlation with the seafloor noise variance, and the vessel to hydrophone angle has a modest negative correlation with both the noise variance and kurtosis, particularly within a certain distance $(6.6 \mathrm{~km}$ at depth $150 \mathrm{~m}$ here). While the range is specific due to it depends on vessel monopole source levels, depth of propeller, depth of the water and the distance to the vessel. As the vessel approaches, the seafloor noise is sensitive to the noise radiated from the vessel manoeuvre dominated at frequencies 400-900 Hz. Further, as the vessel speed increases from 2 knots to 15 knots, the vessel tonal increases the power spectral density (PSD) by 10-20 dB at multiple narrow frequency bands $(770$ and $850 \mathrm{~Hz})$. A drop of the spectral kurtosis over frequency $1.1 \mathrm{kHz}$ also indicates the closest point of approach (CPA).

This paper is organized as follows. Section 2 describes the sea trial and noise measurement in the central North Sea, and Section 3 describes methods of data process and analysis, including variance, kurtosis, correlation, PSD and its standard deviation. Section 4 shows the analysed results. Section 5 completes the paper with concluding remarks, discussions, and gives outlooks for future work. 


\section{Sea trial and noise measurement}

The Goldeneye area, located in the central North Sea, which has been considered as a possible site for a marine carbon sequestration site [56], was selected for this experiment. To conduct the experiment, a cruise (Figure 1) was undertaken in September, 2017. The cruise used the British Royal Research Ship (RRS) 'James Cook', which is owned by the NERC (Natural Environment Research Council), U.K.. It was constructed in 2006 in Norway. Table 1 defines its characteristics.

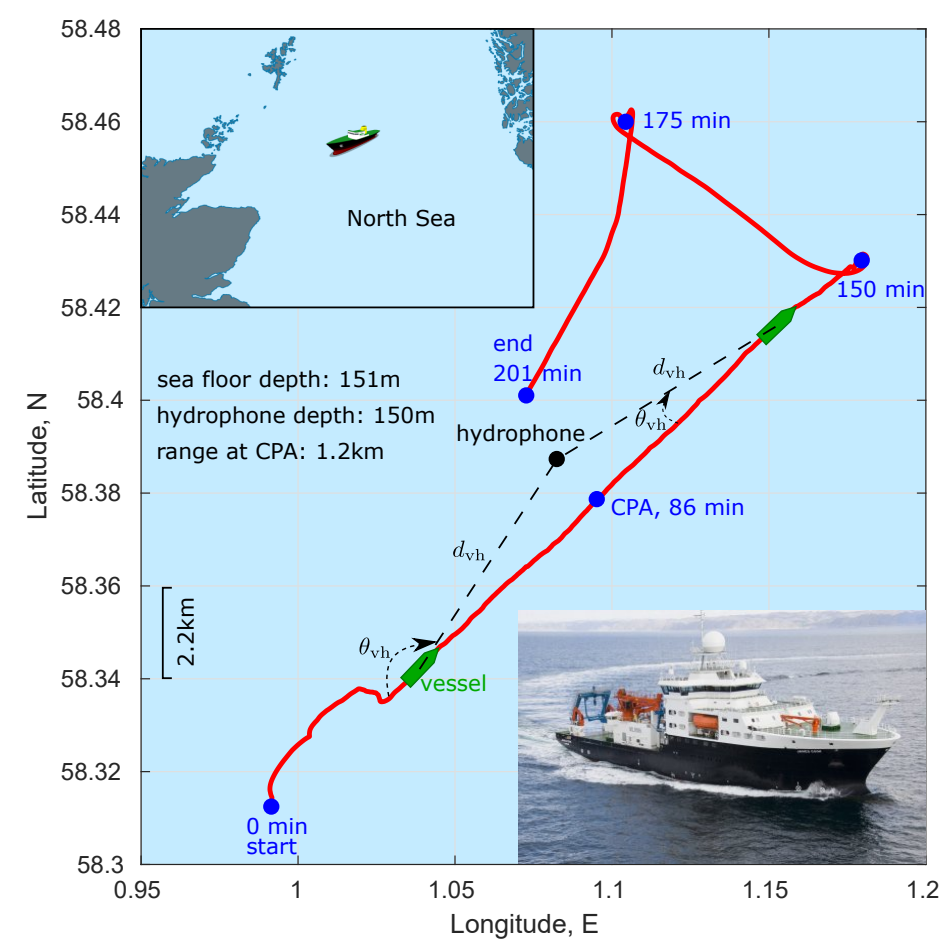

Figure 1: Path of the vessel for the noise measurement (03:33-06:54 a.m. on 11/Sep/2017), lasting 201 minutes. The cruise used the British RRS 'James Cook', and was conducted at a position in the central North Sea about $180 \mathrm{~km}$ from the east coast of Scotland. The distance $d_{\mathrm{vh}}$ and angle $\theta_{\mathrm{vh}}$ from the vessel to the hydrophone were computed through the vessel track. The CPA range was $1.2 \mathrm{~km}$ at the $86 \mathrm{th}$ min. Two looping turns were conducted at the 150 th min and 175 th min.

The seafloor noise measurement used Wildlife Acoustics 'Song meter SM2M' acoustic recorder with a sampling frequency $f_{s}=96 \mathrm{kHz}$. The hydrophone is omnidirectional, which was calibrated to frequencies above $1 \mathrm{~Hz}$ at the National Physical Laboratory, London. It possesses frequency dependent sensitivity, and with sensitivity of about $-165 \mathrm{~dB}$ re $1 \mathrm{~V} / \mu \mathrm{Pa}$ above $30 \mathrm{~Hz}$. When we process the data in frequency, we take the frequency dependent sensitivity of the hydrophone into account. The hydrophone was moored $1 \mathrm{~m}$ horizontally above the seafloor at a depth of $150 \mathrm{~m}$. Note that the 'SM2M' has 2 configurations, i.e., bulkhead mounted transducer and cable mounted transducer. The bulkhead transducer can have a problem with pressure doubling at certain frequencies if the 'SM2M' is mounted vertically. The vessel speed and position (coordinates) were recorded by the Seapath 330plus system, providing accurate navigation and altitude data for use by equipment on board the vessel. A relative position of the vessel and hydrophone is shown in Figure 1. The coordinate of the hydrophone was recorded as $\left(58^{\circ} 38^{\prime} 73^{\prime \prime} \mathrm{N}, 01^{\circ} 08^{\prime} 24^{\prime \prime} \mathrm{E}\right)$. The wind speed was recorded by a Surfmet system equipped on the vessel, removing the vessel motion from the wind speed and direction. The sampling protocol of the two systems acquired data at 1 sample per second.

The data analysed here have been obtained from the observation period 03:33-06:54 a.m. on 11/Sep./2017, starting at $58^{\circ} 31^{\prime} 26^{\prime \prime} \mathrm{N}, 00^{\circ} 99^{\prime} 16^{\prime \prime} \mathrm{E}$ and ending at $58^{\circ} 40^{\prime} 11^{\prime \prime} \mathrm{N}, 01^{\circ} 07^{\prime} 26^{\prime \prime} \mathrm{E}$. During the 201 min observation period, spectrograms at start and end showed no trace of distant shipping. During the sea trial, the tidal level (Figure 2(a)), wind speed/direction (Figure2(b-c)) over the sea surface, vessel speed/direction over ground (Figure 2(d-e)), vessel to hydrophone distance $d_{\mathrm{vh}}$ and angle $\theta_{\mathrm{vh}}$ (Figure $2(\mathrm{f}-\mathrm{g})$ ), and the seafloor noise data were recorded. No precipitation were observed during the measurement. The sound speed profile (SSP) collected in the area is shown in Figure 3(a). The transmission loss (at $60 \mathrm{~Hz}$ as 
Table 1: Characteristics of RRS 'James Cook' 57, 58.

\begin{tabular}{ll}
\hline \hline Deadweight tonnage & $2463 \mathrm{~T}$ \\
Length overall & $89.20 \mathrm{~m}$ \\
Beam & $18.60 \mathrm{~m}$ \\
Service speed, maximum & $16.00 \mathrm{knots}$ \\
Maximum draft & $6.315 \mathrm{~m}$ \\
Type of main propellers & $2 \times$ five-bladed inward turning \\
Propeller diameter & $3.6 \mathrm{~m}$ \\
Propeller depth & $3.5 \mathrm{~m}$ \\
Engine type & Diesel electric \\
Main engine horsepower & $7040 \mathrm{~kW}-$ Wartsila \\
Main propulsion system & Diesel electric propulsion plant \\
& $2 \times 2500 \mathrm{~kW}$ Teco Westinghouse dc mot \\
& $($ speed 0-180 rpm $)$ \\
& $4 \times 1770 \mathrm{~kW}$ Wartsila 9L20 \\
& $(1000 \mathrm{rpm}$ generators sets, 9 cylinders $)$ \\
& $3 \times$ Siemens alternators, 690 V/60 Hz \\
\hline \hline
\end{tabular}

an example chosen from substantial vessel tonal frequency) in the acoustic channel calculated using the Bellhop model [59, 60] with the SSP is shown in Figure 3(b).

\section{Data process and analysis}

The data were recorded on the 'SM2M' with a channel gain of $6 \mathrm{~dB}$. The acoustic noise is processed with 10 s observation windows, thus groups of $K=1206$ noise fragments in time have been statistically analysed. The time window used for the process was suggested to equal the time it took the vessel to travel its length 61, 17. Here we choose $10 \mathrm{~s}$, which keeps both the variance and trend of moment. This means that, if we choose a number much larger than the $10 \mathrm{~s}$, the data will not show the variance; while if we choose a number much smaller than $10 \mathrm{~s}$, the data will be shown much sparse and will not show the trend visually. Relative statistics include variance $(\sigma)$ in broadband power over time (Figure 2(h)), kurtosis $(\beta)$ in broadband power over time (Figure2(i)), correlation coefficient ( $\xi$ ), PSD (Figure 5), and PSD standard deviation (Figure 8), i.e., power variance of the signal as a function of frequency.

\subsection{Variance}

The variance of waveform fragment $k$ in broadband power over time is computed as:

$$
\sigma_{k}=\frac{1}{N-1} \sum_{i=1}^{N}\left|x_{k}(i)-\mu_{k}\right|, k=1,2, \ldots, K,
$$

where $N$ is the total index number of a fragment, $i$ is the sample index in a fragment, and $\mu_{k}$ is the mean of $x_{k}(i)$,

$$
\mu_{k}=\frac{1}{N} \sum_{i=1}^{N} x_{k}(i)
$$

\subsection{Kurtosis}

The kurtosis is one of the properties of non-Gaussian inherent central moments. The kurtosis of waveform fragment $k$ in broadband power over time is computed as:

$$
\beta_{k}=\frac{E\left(x_{k}(i)-\mu_{k}\right)^{4}}{\sigma_{k}^{2}}, k=1,2, \ldots, K,
$$

where $E(\cdot)$ represents the expected value of the quantity. Stationary Gaussian signal (normal) are characterized by a kurtosis equal to 3 [62]. A shift from this value corresponds to a probability density 

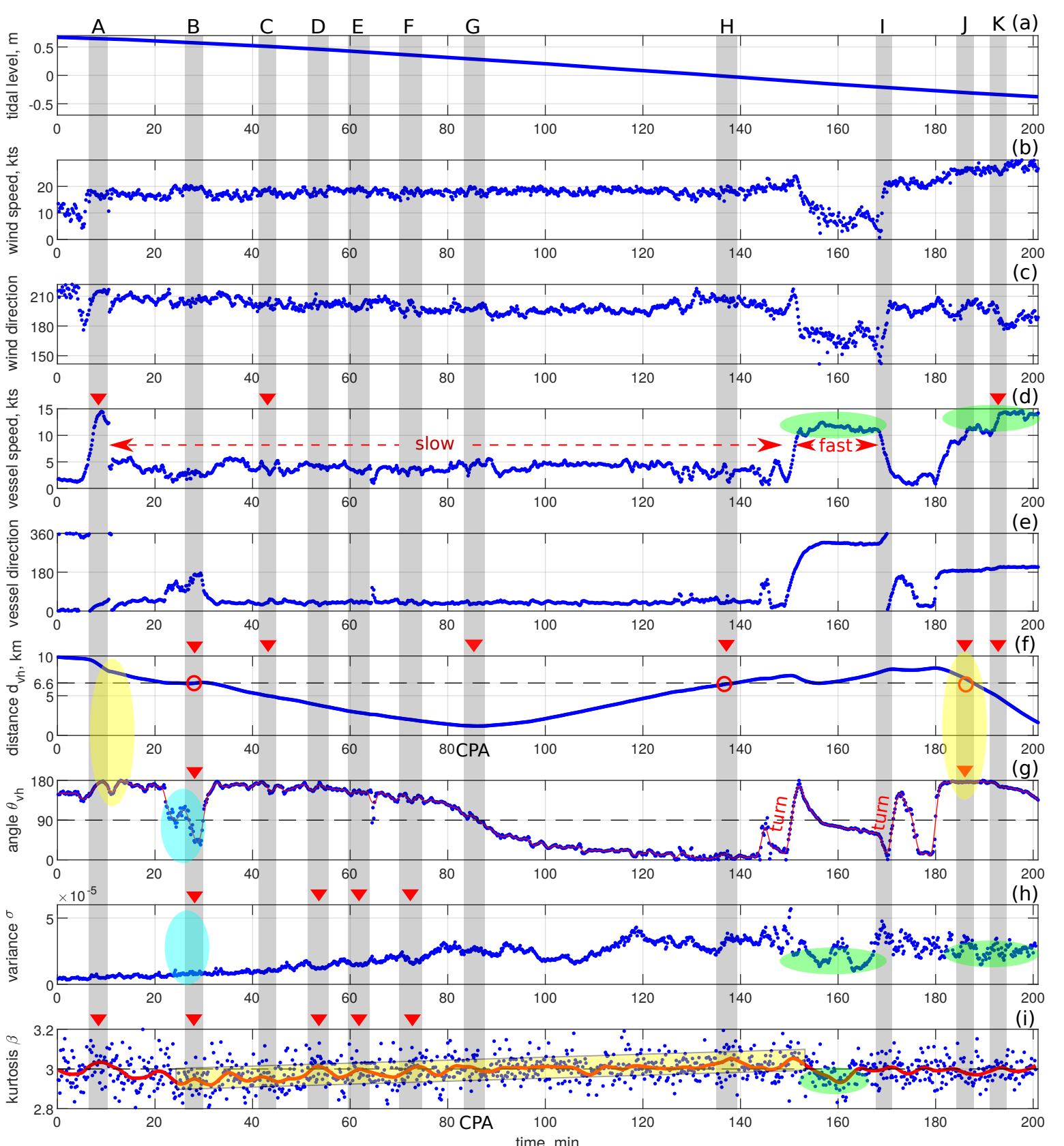

Figure 2: Recorded parameters and characteristics of the seafloor noise (blue dots) and smoothed curve (red line). Black dashed reference lines are plotted as comparison. Grey bars with capital letters (A-K) and red triangles are marked as key features explained through the text. (a) tidal level $[\mathrm{m}]$; (b) wind speed [knots]; (c) wind direction $\theta_{\mathrm{w}}$, degrees north; (d) vessel speed over ground [knots]; (e) vessel direction $\theta_{\mathrm{v}}$, degrees north; (f) vessel to hydrophone distance $d_{\mathrm{vh}}[\mathrm{km}$ ], reference line $d_{\mathrm{vh}}=6.6 \mathrm{~km} ;(\mathrm{g})$ vessel to hydrophone angle $\theta_{\mathrm{vh}}$ [degree]; reference line $\theta_{\mathrm{vh}}=90^{\circ} ;(\mathrm{h})$ acoustic data variance $\sigma ;(\mathrm{i})$ acoustic data kurtosis $\beta$, reference line $\beta=3$. 


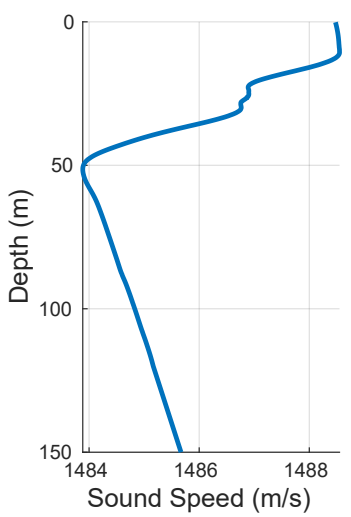

(a)

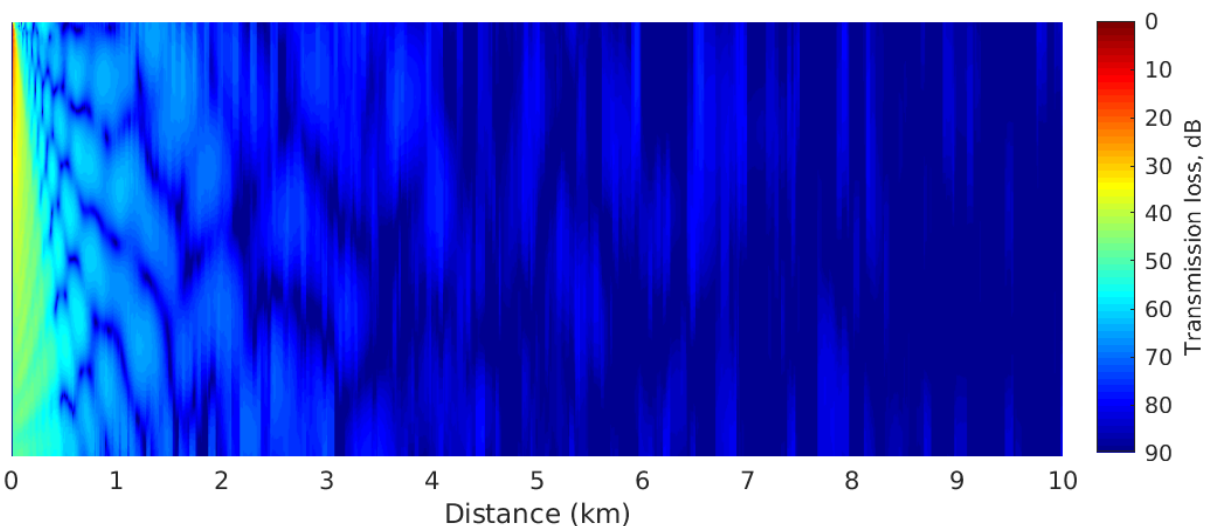

(b)

Figure 3: Sound speed profile (SSP) collected in the central North Sea, and transmission loss within $10 \mathrm{~km}$ in the acoustic channel calculated using Bellhop, showing the TL structure in the channel. The depth of the shipping noise source is set to $3.5 \mathrm{~m}$, which is the propeller depth (Table 1). (a) Sound speed profile; (b) Transmission loss at $60 \mathrm{~Hz}$.

Table 2: Kurtosis configuration of underwater acoustic noise.

\begin{tabular}{lc}
\hline \hline Noise component & Kurtosis \\
\hline Vessel cavitation noise & low $(<3)$ \\
Vessel machinery vibration noise & high $(>3)$ \\
Sea surface noise & high $(>3)$ \\
\hline \hline
\end{tabular}

function (PDF) shape different from a Gaussian distribution. Sinusoidal signals, such as those associated with vessel cavitation noise, are characterised by low values of kurtosis $(<3)$, while impulsive broadband sources, such as sea surface agitation noise and machinery vibration noise, are characterised by high values of kurtosis $(>3) 32$ as summarized in Table 2

However, the central limit theorem (CLT) 63] establishes that, under certain conditions, when independent random variables are added, their properly normalized sum tends toward a normal distribution even if the original variables themselves are not normally distributed. The acoustic channel tends to make the statistic of the output signal 'more Gaussian' 64, which tends to result in the kurtosis of the seafloor noise radiated from the sea surface tending to be 3 and statistically insignificant. A common approach [65, 66] utilises a smoothed version of the kurtosis coefficient. It is smoothed using a span of $5 \%$ of the total number of data points [67. By comparing the smoothed kurtosis coefficient curve with other coefficients (distance $d_{\mathrm{vh}}$ and angle $\theta_{\mathrm{vh}}$ ), we find some relationships and trends described in Section 4.2 .

Several noise sources contribute to ambient noise, in different frequency bands. Wind-generated noise is generally the major contributor at frequencies above $100 \mathrm{~Hz}$, but in the presence of a vessel, it should be above some $\mathrm{kHz}$, because such vessel noise generally dominates the underwater noise below $1 \mathrm{kHz}$. Computing Kurtosis in global broadband (in waveform without filtering) cannot highlight which source is the major contributor to the noise budget. Thus a spectral kurtosis of waveform could provide more information on the acoustic characterization from different sources. To find the frequency dependent kurtosis characteristics, we choose a frequency threshold and compute the spectral kurtosis from high/low-pass filtered waveform.

\subsection{Correlation coefficient}

To show the strength of linear relationship between two variables, the Pearson correlation coefficient 68 is used as

$$
\xi=\frac{\sum_{k=1}^{K}\left(\varphi_{1}(k)-\bar{\varphi}_{1}\right)\left(\varphi_{2}(k)-\bar{\varphi}_{2}\right)}{\sqrt{\varepsilon_{1}^{2}} \sqrt{\varepsilon_{2}^{2}}},
$$


where

$$
\varepsilon_{1}^{2}=\sum_{k=1}^{K}\left(\varphi_{1}(k)-\bar{\varphi}_{1}\right)^{2},
$$

and

$$
\varepsilon_{2}^{2}=\sum_{k=1}^{K}\left(\varphi_{2}(k)-\bar{\varphi}_{2}\right)^{2},
$$

are covariance of the variables, $\varphi_{1}(k)$ and $\varphi_{2}(k)$ are the two variables, $\bar{\varphi}_{1}$ and $\bar{\varphi}_{2}$ are mean values of the two variables, respectively. Values between 0 and 0.3 ( 0 and -0.3) indicate a weak positive (negative) linear relationship via a shaky linear rule; values between 0.3 and $0.7(-0.3$ and -0.7$)$ indicate a moderate positive (negative) linear relationship via a fuzzy-firm linear rule; and values between 0.7 and 1.0 (-0.7 and -1.0) indicate a strong positive (negative) linear relationship via a firm linear rule 68.

\subsection{Power spectral density (PSD)}

A general quantitative description of the seafloor noise can be provided by the analysis of PSD. The noise PSD is estimated using the Welch's PSD estimate technique [69, which is a common approach for obtaining signal PSD. It works on the chosen noise period with $f_{s} / 2$ points overlapping, to reduce the variance of the periodogram, breaks the time series into segments, and returns one-sided Welch PSD estimates [69]:

$$
\left[\mathrm{PSD}_{k}\right]=\operatorname{pwelch}\left(x_{k}(i)\right), k=1,2, \ldots, K,
$$

where the 'pwelch' represents the Welch's PSD estimate technique [69, a hamming window of equal length $f_{s}$ is used, and the NFFT size is chosen as $f_{s} / 2$. The $\mathrm{PSD}_{k}\left[\mathrm{~dB} \mathrm{re} \mu \mathrm{Pa}^{2} / \mathrm{Hz}\right]$ for the $k$ th fragment is finally computed with considering the gain and frequency dependent sensitivity of the hydrophone known from design specification. Thus, the estimate of the noise PSD would be the average at each time fragment.

\subsection{PSD standard deviation}

To find the acoustic sensitivity of the seafloor noise and the power variance of the signal as a function of frequency, the PSD standard deviation $\rho$ is evaluated for each $2 \min (J=12$ fragments). The $m$ th min $\rho_{m}$ is computed as:

$$
\rho_{m}=\sqrt{\frac{1}{J-1} \sum_{j=1}^{J}\left|\operatorname{PSD}_{m}(j)-\mu_{m}\right|}, j=1,2, \ldots, J,
$$

where $\mu_{m}$ is the mean of $\operatorname{PSD}_{m}(j)$.

\section{Results}

One objective of the measurement program was to measure the seafloor noise ensemble for a research vessel transiting within $10 \mathrm{~km}$ of a bottom mounted hydrophone in the central North Sea for a required SNR of processing seabed acoustic signals. The secondary objective was to determine the effect of environment parameters (e.g., tide, wind) on the seafloor noise. The data were evaluated using variance, kurtosis, correlation coefficient, PSD, and PSD standard deviation. Figure 2(a-g) show the recorded parameters, and Figure 2(h-i) show the resulting variance and kurtosis.

\subsection{Variance}

Variance of the recorded seafloor noise reveals the scatter level from the mean value of the noise power, which is affected by the surrounding noise sources, e.g., vessel and wind-waves. For the vessel, the time-varying distance $d_{\mathrm{vh}}$ resulted in a time and frequency varying transmission loss, as shown in Figure 3(b). Frequency dependent absorption is also a well known effect. It will obviously increase the variance of power with respect to frequency.

The vessel approached the hydrophone on two occasions (The downward scoping areas in Figure 2(f)). The first approach is from the start to bar G, and the second approach is from bar I to the end. The variance from the first approach increased by five times, due to the reduced distance $d_{\mathrm{vh}}$ (Figure 2(f)) 
and reduced tidal level (Figure 2(a)), allowing less transmission loss in the underwater channel, where reflection, refraction, scattering, and frequency dependent absorption affect the noise propagation. Additionally the vessel underwater radiated noise varies with vessel azimuth [3, which can be revealed in the fluctuation of the variance as the vessel transits past. From bar A to D, the variance is creasing while the angle was relatively stable due to the reduced distance associated with increased machinery noise. At minute $\sim 25 \mathrm{~s}$, there is no corresponding change in variance with angle at the low vessel speed (2-3 knots), which is below the cavitation inception speed. In the approaching period from bar B to $\mathrm{F}$ (angle $\theta_{\mathrm{vh}}>90^{\circ}$ ), the variance increases as the distance $d_{\mathrm{vh}}$ and angle $\theta_{\mathrm{vh}}$ decrease (Figure 2(g-h)). At minute $15 \mathrm{~s}$ and minute $190 \mathrm{~s}$ the vessel aspect and range are similar but the variance is different, which is accounted for the different vessel speeds ( 5 knots versus 12 knots). At minutes $\sim 160 \mathrm{~s}$ and the end, the high vessel speed (Figure 2(d)) made high cavitation noise which resulted in low variance (Figure 2(h)) due to the relatively stable cavitation. At minutes $\sim 15 \mathrm{~s}$ and $\sim 187 \mathrm{~s}$, the distance $(\sim 7 \mathrm{~km})$ and angle $\sim 180^{\circ}$ are similar, the first has low variation while the second has high variation (Figure $2(\mathrm{~h})$ ), which is due to the high speed associated with high machinery vibration noise because the cavitation at such bow aspect has weak impact. The variance does not correlate well to vessel speed, vessel aspect, distance or wind. Something else is driving this, i.e., tidal level (Figure 2(a)), seafloor, swell or sound speed profile affecting the propagation (Figure 3).

The propeller noise is normally reduced forward by the vessel body and poorly propagates towards the bow of the vessel [70], while the machinery noise (vibration of the shell plates) can propagate forward in some cases. The $\sim 20$ knots winds during the measurements resulted in $\sim 2 \mathrm{~m}$ swell (sea state 5 ) and whitecaps were observed. Swell creates very low frequency noise, while breaking waves create much broaden frequency noise. Note that swell noise can be filtered by the hydrophone if not accurately accounted for. The 20 knots wind speed and $2 \mathrm{~m}$ waves will increase the noise level at high frequencies.

\subsection{Kurtosis}

The kurtosis coefficient (Figure 2(i)) varies in an interval of [2.8 3.2], showing a distribution close to normal distribution $(\beta=3)$, because of the additive process of the noise in the underwater channel. Low kurtosis values are associated with broadband noise source, e.g., propeller cavitation, while high kurtosis values are indicative of tonal sources, e.g., machinery vibration noise 64. Breaking waves tend to be greater than 3 . The dashed line $(\beta=3)$ is used for comparison and shows the kurtosis curve (solid red line) tending above or below 3 .

In the period from bar B to $\mathrm{G}$, the kurtosis shows an increasing trend (Figure 2(i), red line, yellow box), which is interpreted to the increasing machinery vibration noise. In this approaching period, even though the cavitation noise was increased (from bar B to F), the machinery noise was increased even faster. This feature is also shown in the period from bar $\mathrm{J}$ to the end, and only exists when the distance $d_{\mathrm{vh}}$ is less than $6.6 \mathrm{~km}$ (cross points, marked as red circles in Figure 2(f)). From bar G to H, the kurtosis was relatively stable due to the hydrophone was in the radiation pattern of the cavitation noise source. Also, the cavitation noise was much more stable than that of breaking waves from the vessel hull, especially in such a fresh sea state 5 . At minute $\sim 160 \mathrm{~s}$, the low kurtosis was resulted from the high cavitation associated with the fast manoeuvre (Figure 2(d)).

The dominant radiated noise over the broadband can be located at the low frequencies below around $1.1 \mathrm{kHz}$ (Figure 5(a) \& Figure 9(a)), at which the sea surface acts as pressure release boundary causing a phase shift of $180^{\circ}$ on the reflected waves [71. Underwater multipath propagation, including the direct path and sea surface reflected path, superimpose at the acoustic recorder and interfere with each other causing constructive and destructive interference of waves from the two paths, which is normally called the Lloyds' Mirror Effect [72, 73. There are three obvious kurtosis increases in the bar D, E and F, which show a negative correlation between the kurtosis and the variance, corresponding to the reduced PSD at frequency tones of about $50 \mathrm{~Hz}$ and $60 \mathrm{~Hz}$ as shown in Figure 5(b). This is interpreted to the Lloyds's Mirror Effect [15], shown as 'U' curves in Figure 5(b). The level of the Lloyds' Mirror Effect depends on the source/receiver depth and the shape of the sea surface, which will not be discussed here in detail.

The kurtosis of broadband and filtered waveform is shown in Figure 4 . The low-pass filtered waveform has similar kurtosis with that of the broadband waveform, while the high-pass filtered waveform shows quite different kurtosis feature. The wind is interpreted as the major contributor of this kurtosis above 3 , as it is relatively stable during the measurement. A sudden drop of the value at around the CPA in Figure 4(c) can be observed, which is due to the cavitation is line of sight to the hydrophone starting 
from the CPA reducing the kurtosis. This feature can be helpful to identify the CPA of a transiting vessel.

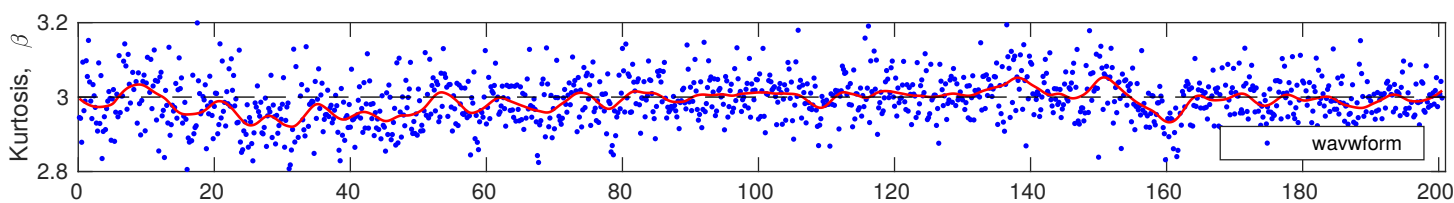

(a)

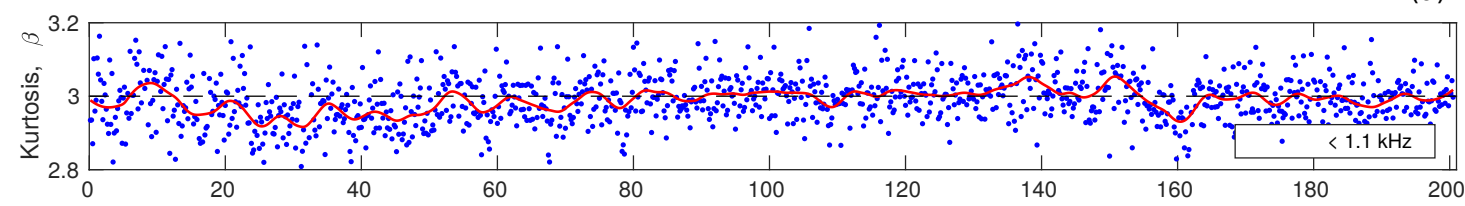

(b)

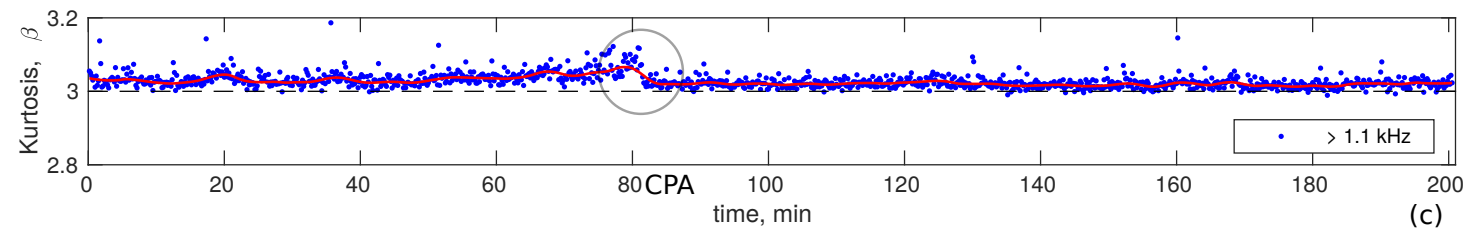

Figure 4: Broadband and spectral kurtosis comparison. (a) global broadband waveform; (b) low-pass filtered waveform $(<1.1 \mathrm{kHz})$, similar to that of the broadband waveform; (c) high-pass filtered waveform $(>1.1 \mathrm{kHz})$, showing a sudden kurtosis drop around the CPA (circled).

\subsection{Correlation coefficients}

Table 3 shows the overall correlation coefficients computed from Eq. (4). As a result, the tidal level shows a strong negative correlation with the acoustic data variance. This may due to less acoustic channel interference added to the shipping noise as the vertical distance between the vessel and the hydrophone reduces. The angle $\theta_{\mathrm{vh}}$ shows modest negative correlation with the variance and kurtosis. As expected, the variance reduces as angle reduces associated with the more stable cavitation radiation noise; and the kurtosis reduces as the level of cavitation noise increases. The remaining pairs show weak correlations, and the vessel speed has almost no linear relationship with the variance and kurtosis of the acoustic data

Table 3: Overall correlation coefficients.

\begin{tabular}{lcc}
\hline \hline Coefficient & Variance & Kurtosis \\
\hline Tidal level & $\mathbf{- 0 . 7 7}$ & -0.29 \\
Wind speed & 0.29 & 0.23 \\
Vessel speed & 0.05 & 0.06 \\
Distance $d_{\mathbf{v h}}$ & -0.14 & -0.03 \\
Angle $\theta_{\mathbf{v h}}$ & $\mathbf{- 0 . 6 5}$ & $\mathbf{- 0 . 4 1}$ \\
\hline \hline
\end{tabular}

\subsection{Power spectral density (PSD)}

PSD are qualitative visualizations of the record features, to enhance low-frequency features, it is semi-logarithmically presented in Figure 5(a) for all levels and frequencies. It illustrates the temporal and spectral variation of the underwater noise in the presence of the vessel. The most prominent feature is the high variability at low frequency band $(<1 \mathrm{kHz})$ as dominated by shipping noise, and only a modest ensemble variability in the high frequency band $(>1 \mathrm{kHz})$ as dominated by wind wave, denoting a combination of noise from different sources.

As the vessel approaches (from the beginning to the CPA), a general increase of noise level can be observed, because of the reduced propagation loss in the channel. In the interval between the bar $G$ and $\mathrm{H}$, the PSD changes are relatively modest, due to the relatively constant wind speed, vessel speed and line of sight to the propeller (Figure $2(\mathrm{~b}),(\mathrm{d}), \&(\mathrm{~g})$ ). During the transit away from the hydrophone, 


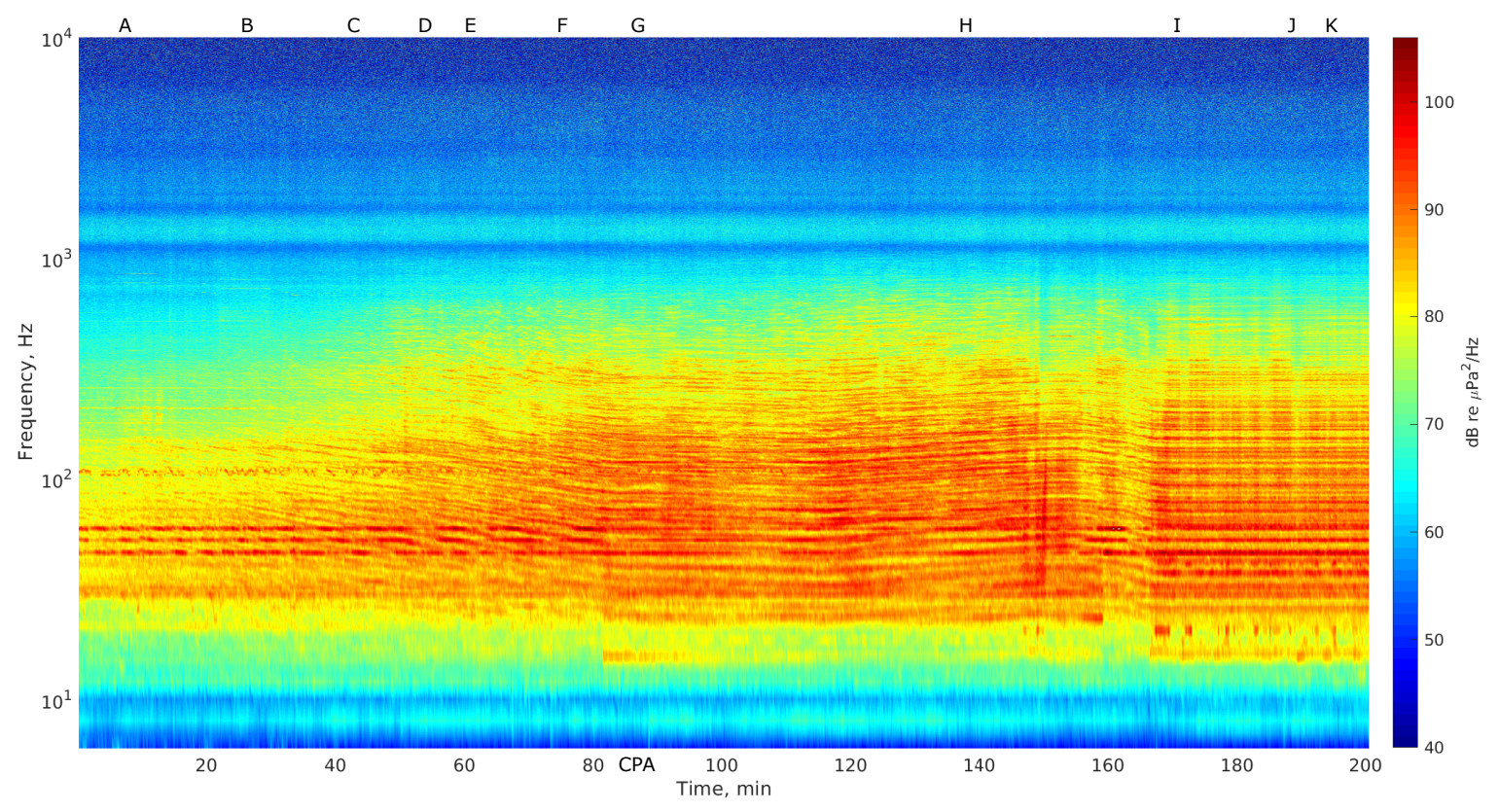

(a)

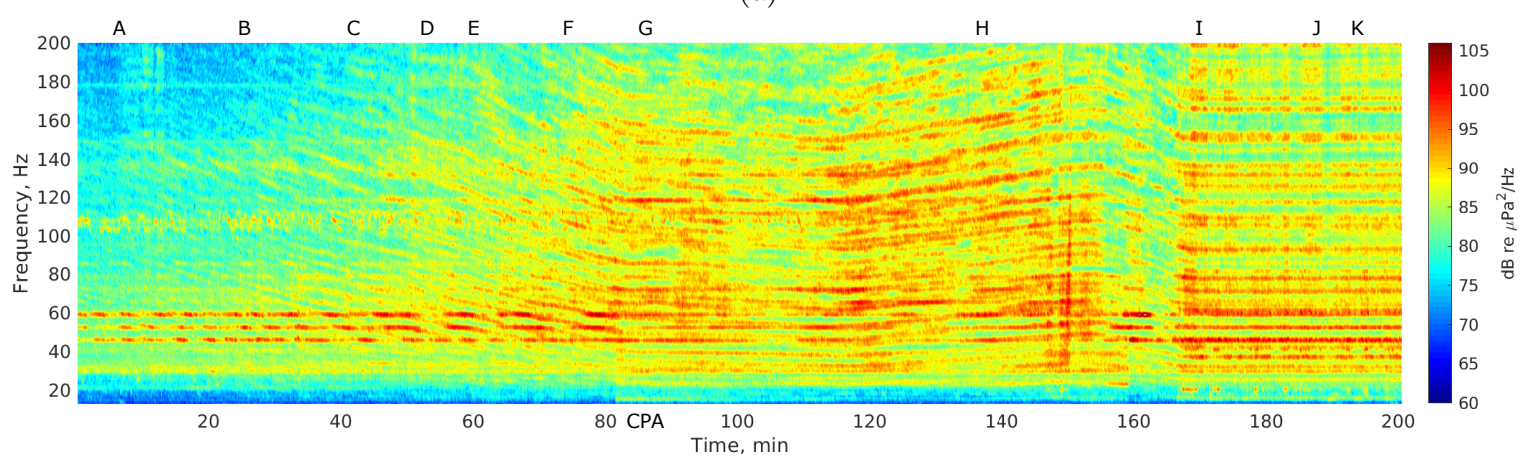

(b)

Figure 5: Power spectral density using 10-s window averages. Variation in levels received by the hydrophone in the presence of a research vessel transiting nearby. Capital letters respond to the capital letters in Figure 2 for marking. (a) Full spectrogram over the range $6 \mathrm{~Hz}-10 \mathrm{kHz}$; (b) DEMON spectrogram over 10-200 Hz, 'U' shape curves showing the Lloyds' Mirror Effect. 
the cavitation is line of sight to the hydrophone. In this case, it is low frequency, i.e., $<1 \mathrm{kHz}$ so attenuation is low, and spreading cylindrical not spherical at this water depth and range. The wind speed and the vessel speed during the period from bar $\mathrm{G}$ to $\mathrm{H}$ are relatively consistent, hence providing relatively constant kurtosis (Figure 2(i)) and PSD (Figure 5). However, from bar H to I, the PSD changes significantly as the vessel aspect changes. At the end (starting from bar J), the PSD tends to modest again because of the same aspect of the vessel.

The next most apparent as well as particularly surprising feature is the elevation in spectral levels in the time period around bar $\mathrm{A}$ at frequencies between $760 \mathrm{~Hz}$ and $860 \mathrm{~Hz}$ (Figure 6). Levels in this spectral band, are known to correlate well with vessel speed increased from 2 knots to 15 knots and then 5 knots (see Figure 2(d)). It can be seen most prominently in the spectrograms at frequencies $400 \mathrm{~Hz}-1 \mathrm{kHz}$ that it was relatively quiet at the seafloor until the vessel speed reached 15 knots. At such distance of 8-9 km, vessel speed 2 knots corresponds to a PSD less than $60 \mathrm{~dB}$ re $\mu \mathrm{Pa}^{2} / \mathrm{Hz}$. As the vessel speed increased from 2 knots to 15 knots, the seafloor noise PSD constitutes an increase of $10 \mathrm{~dB}$ at the frequency band $770-775 \mathrm{~Hz}$, and an increase of $20 \mathrm{~dB}$ at the frequency band $845-850 \mathrm{~Hz}$. The feature represents vessel tonal noise and correspond to the increase in vessel speed, where the elevation exists at multiple separated narrow frequency bands rather than at a single broad band. These are the kind of real-world effects that complicate the attempt to model the seafloor noise and shows the necessity and importance of this research on guaranteeing high enough SNR on acoustic signal processing at specific frequencies.

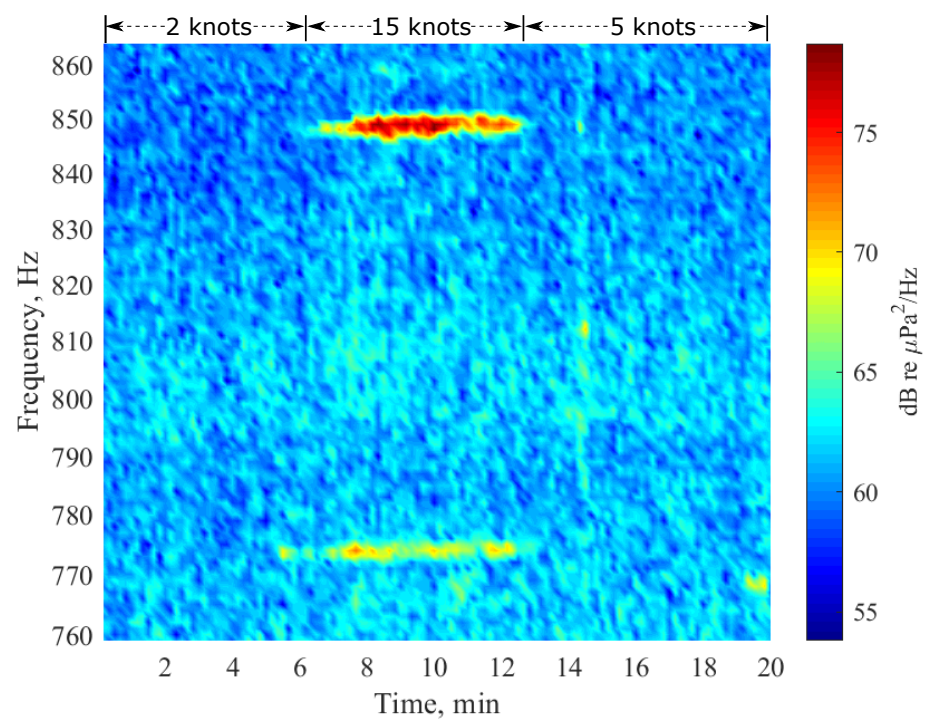

Figure 6: PSD variation at frequencies $760-860 \mathrm{~Hz}$ in levels received by the hydrophone as vessel speed changed from 2 knots to 15 knots, and then 5 knots at distance 8-9 km shown in Figure 2 d), bar A. Such vessel tonal noise are only observed at vessel speed of 15 knots at such distance.

Analysing the ambient noise on the spectrograms is possible, but third-octave bands provide a further in-depth outlook on noise levels across the frequency composition. Figure 7 shows the third-octave bandwidth spectra in the two approaching periods at the 43rd min (bar C) and the 193rd min (bar J) as well as the recorded background noise while the ship was stable. In both cases, the scenarios were similar (wind speed 15-20 knots, horizontal distance $d_{\mathrm{vh}}=5 \mathrm{~km}$, and angle $\theta_{\mathrm{vh}}=150^{\circ}$ ), while the corresponding vessel speeds were different, 4 knots and 14 knots, respectively. This figure shows that the spectrum has a broad, high-level prominent 'hump' at frequencies $40-80 \mathrm{~Hz}$, which is a typical feature in shipping noise spectra [25, 31]. It is followed by a continuum that decreases by 5-9 dB per octave on a constant-bandwidth. Data on seafloor noise at vessel speed 14 knots indicates that shipping noise constitutes a $5 \mathrm{~dB}$ elevation of seafloor noise levels in the low frequencies up to $1.2 \mathrm{kHz}$ relative to that at vessel speed 4 knots. This is vessel specific and as mentioned above the generation depends on vessel characteristics. 


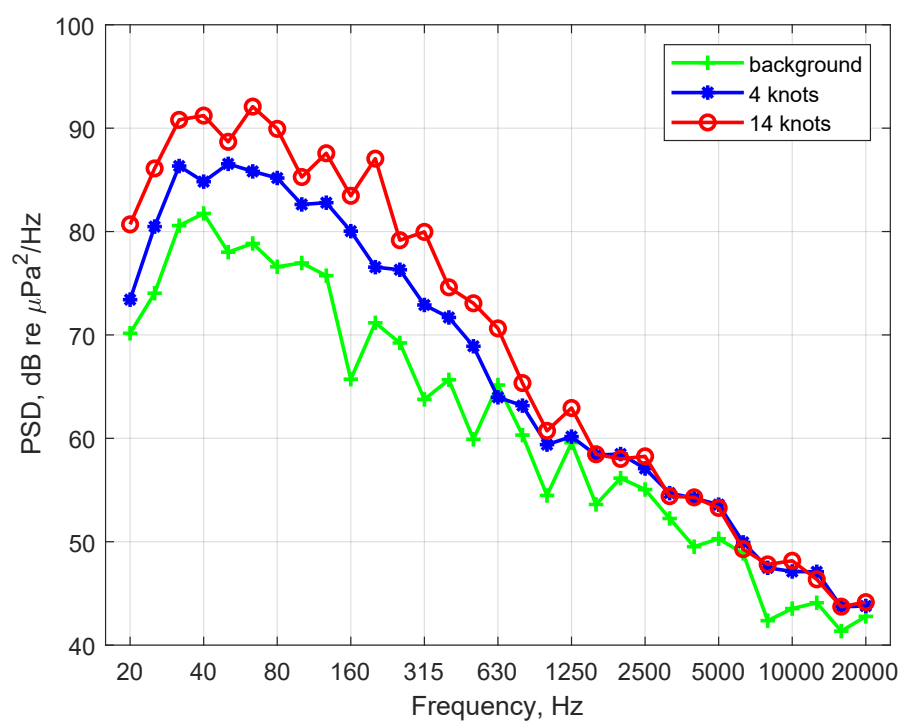

Figure 7: Third-octave bandwidth spectra in the two approaching periods at the 43rd min (vessel speed 4 knots), and the 193rd min (vessel speed 14 knots), as well as the background noise. The scenarios were similar (wind speed 15-20 knots, distance $d_{\mathrm{vh}}=5 \mathrm{~km}$, and angle $\theta_{\mathrm{vh}}=150^{\circ}$ ), apart from the corresponding vessel speeds.

\subsection{PSD Standard deviation}

To provide quantitative measurements of the seafloor noise variability, we have computed the ensemble PSD standard deviation of the spectrum level as a function of frequency and time. The standard deviations were found to be about $0-7 \mathrm{~dB}$, depending on the noise variability, as shown in Figure 8 The figure indicates the high complexity of the noise ensemble in the measurement period, both in frequency and time. For the first part of the approaching period (from the beginning to bar B), the standard deviation of the spectra varies significantly at frequencies 50-75 Hz and their harmonics (e.g., the prominent value $106 \mathrm{~Hz}$ ) due to vessel manoeuvres, and primarily Lloyd's Mirror variations after bar B.

For the second part of the approaching period, obvious deviation, increasing from $3 \mathrm{~dB}$ to $7 \mathrm{~dB}$, can be seen from $400 \mathrm{~Hz}$ to $900 \mathrm{~Hz}$, corresponding to bubble clouds regime at the bow of the vessel, because of the unstable breaking waves surrounding the vessel bow and consistently reduced distance $d_{\mathrm{vh}}$ and channel transmission loss. This can also be confirmed by the sharply decrease standard deviation at the 87 th min due to the forward radiation pattern of the vessel machinery vibration and bow wave breaking noise. However, it is not significant during the leaving period (from bar $\mathrm{G}$ to $\mathrm{H}$ ), because the cavitation is more constant than the vessel machinery vibration and bow breaking waves.

In the period between the $150 \mathrm{~min}$ and $175 \mathrm{~min}$, two big turns (see Figure 1) were conducted which made complex noise changes across the frequency band $(50 \mathrm{~Hz}-1 \mathrm{kHz})$. At the very end, multiple peaks at frequencies around $20 \mathrm{~Hz}$, sometimes as high as $7 \mathrm{~dB}$, are interpreted to the fluctuations in blade rate levels for significant changing (increasing) the vessel speed or rudder flutter during turns as shown in Figure 2(d). Taken together, these results indicate that the ensemble variability in the total spectrum is not due to single noise source, and for these frequencies the seafloor noise ensemble variability changes as the vessel noise sources change.

\subsection{Narrow-band spectral analysis}

Since this work is primarily concerned with seafloor noise, and spectral signature of the research vessel peaks around $60 \mathrm{~Hz}$, it will prove useful to show tones at frequencies 10-200 Hz. The recorded noise data show high-level tonal frequencies from the vessel's service generators, main engine firing rate, and blade rate harmonics due to propeller cavitation. Figure 9 shows the seafloor aspect narrow-band power spectrum in $1 \mathrm{~Hz}$ bands at distances of $10 \mathrm{~km}$ (1st min) and $1.2 \mathrm{~km}$ (84th min CPA) as well as the recorded background noise as the ship was stable. In both cases, the vessel speed were 2-3 knots.

At the distance $10 \mathrm{~km}$ (Figure 9, dashed blue line), tonal components from the vessel's diesel generator $(60 \mathrm{~Hz})$ and their higher harmonics contribute the seafloor ambient noise power peaks, which is independent of vessel speed. As it is easily distinguished in the curve, related features, most evident 


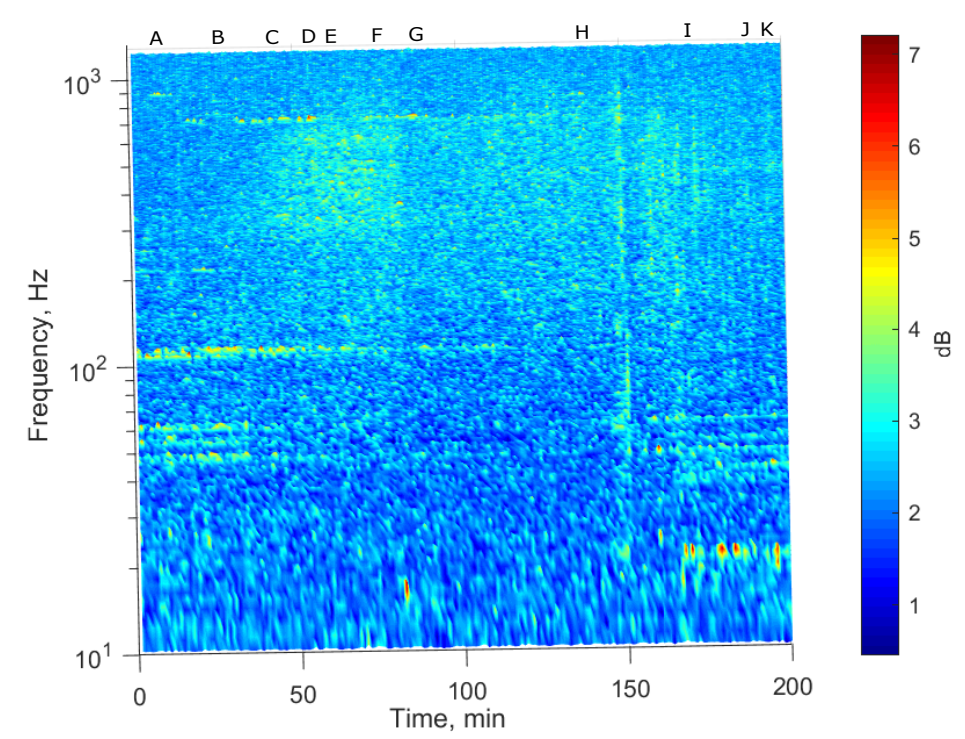

Figure 8: Frequency-dependent ensemble PSD standard deviation for the spectrum level in the function of frequency along time.

in the spectrogram, are the lower peak $(27 \mathrm{~Hz})$ and higher peak $(106 \mathrm{~Hz})$. The especially prominent peak near $106 \mathrm{~Hz}$, is a higher harmonic of the $53 \mathrm{~Hz}$ tone. A lower harmonic component is shown at $27 \mathrm{~Hz}$, although this component is not prominent on the curves, because the variability of the noise source and the propagation channel. Two of these harmonics, at about 53 and $59 \mathrm{~Hz}$, are strong enough to be contributors at the distance $1.2 \mathrm{~km}$ (Figure 9, solid red line). For both tones, the seafloor noise levels are $94.3 \mathrm{~dB}$ re $1 \mu \mathrm{Pa}^{2} / \mathrm{Hz}$. Each 'Wartsila 9L20' diesel generator on the vessel has nine cylinders. Uneven vibration levels of individual cylinders may account for the higher levels of the harmonics that are multiples of nine (about $106 \mathrm{~Hz}$ with level $91.7 \mathrm{~dB}$ re $1 \mu \mathrm{Pa}^{2} / \mathrm{Hz}$ ). With $1000 \mathrm{RPM}, 4$ plants, and 9 cylinders, the vessel could generate $1000 / 2 \times 9 / 60=75 \mathrm{~Hz}$ firing rate and $16.7 \mathrm{~Hz}$ shaft rate. Thus with 1 to 4 generators running, the noise frequency could be $16.7,33.4,50.1$, and $66.8 \mathrm{~Hz}$, all of which can roughly be observed in Figure 5(b). Figure 9(b) also shows that only low frequency tonal components at $10 \mathrm{~km}$ are substantially higher than that of background noise. Apart from these tonal components, the sound levels measured at $10 \mathrm{~km}$ and in the ship condition of stable are similar. This indicates that noise radiated from the ship at such range $(10 \mathrm{~km})$ in the central North Sea does not influence habitats much, particularly for marine animals communicating using high frequencies, such as dolphins, tooth whales, and porpoises.

At the distance $1.2 \mathrm{~km}$, more tones are visible, likely related to the diesel generators, the propulsion diesel firing rate, reduction gear box, or the blade rate; other peaks can be from beat frequencies between the harmonics of the noise sources [15. The multitude of peaks causes ambiguity in the interpretation of sources of the overlapping harmonics and makes the analysis of the spectra data in harmonics even more difficult, especially in such a sea state 5 with $2 \mathrm{~m}$ high swell. Since the radiated shipping noise levels are very sensitive to the distance $d_{\mathrm{vh}}$ and the bathymetry. This is a very complex hydroacoustic problem, and all these tones are considered as dominated by the vessel machinery noise. Some studies have been undertaken to determine sources of these tones from modern ships [15, 70, while the discussion of these tonal components radiated from the vessel in detail is out of the scope in this article.

\section{Conclusions and discussions}

The paper deals with shipping noise as measured at the ocean bottom as a research vessel manoeuvring within $10 \mathrm{~km}$ over the sea surface. We analysed the variance, kurtosis, PSD, and PSD standard deviation of the seafloor noise, to show the ensemble of multiple noise sources, incorporating impacts from the tide, wind speed/direction, vessel speed/direction, vessel to hydrophone distance and angle. We showed that the vessel manoeuvres and aspect can affect the seafloor noise significantly in various conditions. The seafloor noise is dominated by multiple vessel tones. With the investigated vessel, the PSD of the seafloor noise can be increased by $5 \mathrm{~dB}$ at frequencies up to $1.1 \mathrm{kHz}$ as the vessel speed increases from $4 \mathrm{knots}$ 


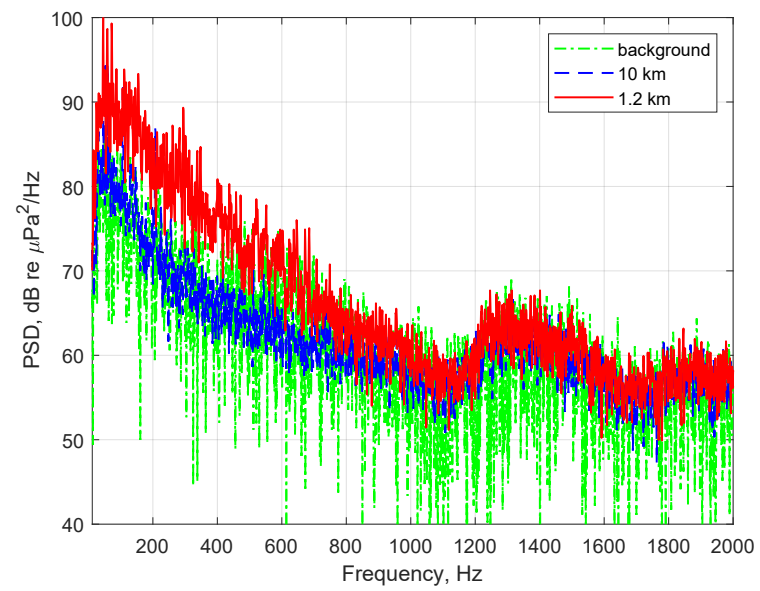

(a)

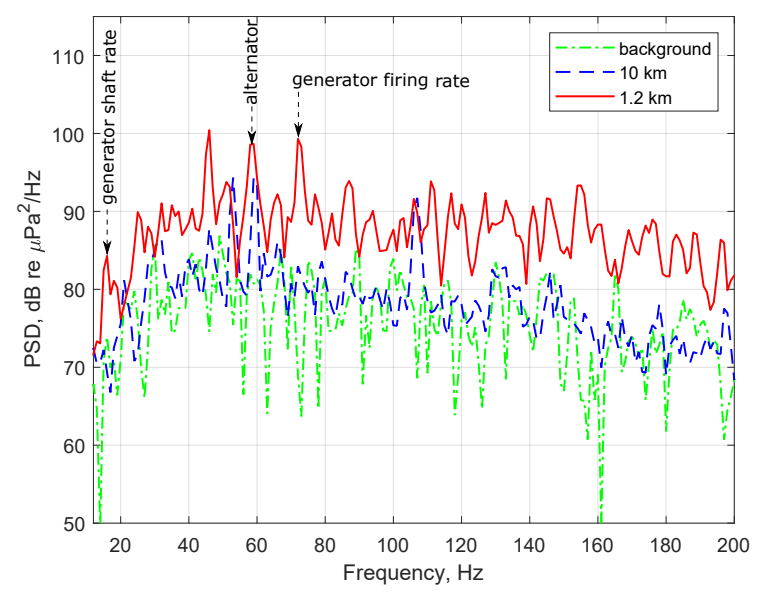

(b)

Figure 9: PSD comparison among the 1 st min (very beginning, $10 \mathrm{~km}$ ), the 87 th min (just after the CPA, $1.2 \mathrm{~km}$ ), and the background noise. The vessel speeds were about 2-3 knots, and the vessel aspect were bow and a beam, respectively. Vessel speed at 3 knots was below cavitation inception speed. The vessel shaft rate 0-180 RPM means 0-3 Hz, the blade rate $0-15 \mathrm{~Hz}$, and the 2 propellers $0-30 \mathrm{~Hz}$. (a) up to $2 \mathrm{kHz}$; (b) up to $200 \mathrm{~Hz}$.

to 14 knots. Further, only increased to about 15 knots, the vessel tonal noise can subsequently impact the seafloor noise at $10 \mathrm{~km}$, and this impact occurred in multiple separated narrow bands above $400 \mathrm{~Hz}$. Correlation between the tidal level, vessel to hydrophone angle, noise variance and kurtosis were found through the analysis. The analysis methods are applicable to most global seafloor acoustic operations, whereas the results can be different with water depth, water conditions, bottom bathymetry and range.

A discussion of the accuracy of these results depends on the equipment used for measurement, signal processing procedure, and the measurement time and environment. Hydrophone system 'Song Meter SM2M' was absolutely calibrated, therefore its absolute calibrations are likely accurate to approximately $1 \mathrm{~dB}$. The frequency dependent hydrophone sensitivity was accounted in the data processing. The amplifier remains as much as $1 \mathrm{~dB}$ bias. The seabed terrain was not accurately measured, which may provide useful information on explaining of the noise attenuation variability in the underwater acoustic channel. Also, specific measurement in the absence of vessel in the same area can provide useful baseline comparison. Longer measurement could be useful to provide more information on the correlation between measured environmental parameters (e.g., tidal level) and acoustic data characteristics.

At the vessel to hydrophone distance $10 \mathrm{~km}$, we fortunately obtain two small noise pieces in the condition of vessel speeds as high as 15 knots and find that only in this condition the PSD of the seafloor noise can be substantially increased by the vessel speed in the central North Sea. Measurements on the vessel speed and wind speed related underwater noise, including near seafloor, need to be conducted and analysed, which will provide more information for accurate and comprehensive statistical modelling. In order to further elucidate the features of the seafloor ambient noise ensemble in the presence of nearby transit vessel(s), we must seek opportunities for more specific measurements including seabed terrain and bathymetry and, furthermore, pursue "frequent and continued measurement" at different sites. The quantitative laboratory work, if applied to vessels and wind variation, would be expected to make the ensemble clearer.

This work documents characteristics of the seafloor noise data in the presence of a transit research vessel and time-varying tide and sea surface wind speed. The planned efforts in parametric analysis and extension to seafloor ambient noise measurement were not completed. Choosing the central North Sea as the experiment site was primarily to estimate the effect of shipping noise on supporting the seabed acoustic research of the greenhouse gaseous bubble leakage detection, localisation and quantification (http://www.stemm-ccs.eu), as well as far from the shore avoiding influence from other anthropogenic noise. It is hoped that these measured data and analysis approaches can provide information on noise predictions used in scientific and engineering seafloor acoustic operations and help to facilitate further efforts to develop models of seafloor noise as the vessel manoeuvre and environment changes. 


\section{Acknowledgments}

Funding for this work was provided by NERC grant NE/N01610/1 and the European Unions Horizon 2020 research and innovation programme under the grant agreement number 654462 (STEMM-CCS). We are grateful to Jonathan Bull and Dan Ellis for collecting the passive acoustic data, as well as the Captain of the RRS 'James Cook' and crew for enabling the scientific measurements at sea during the JC152 cruise.

\section{References}

[1] R. S. Newton, R. C. Cunningham, C. E. Schubert, et al., Mud volcanoes and pockmarks: seafloor engineering hazards or geological curiosities?, in: Offshore Technology Conference, Houston, Texas, U.S., Offshore Technology, 1980, pp. 1-12. doi:10.4043/3729-MS

[2] D. B. Prior, J. R. Hooper, Sea floor engineering geomorphology: recent achievements and future directions, Geomorphology 31 (1) (1999) 411-439. doi:10.1016/S0169-555X(99)00090-2.

[3] K. Abrahamsen, The ship as an underwater noise source, in: Proceedings of Meetings on Acoustics ECUA2012, Vol. 17, ASA, 2012, p. 070058. doi:10.1121/1.4772953

[4] X. Lurton, An introduction to underwater acoustics: principles and applications, Springer Science \& Business Media, 2002. doi:10.1029/2003E0280007

[5] S. Harsdorf, M. Janssen, R. Reuter, S. Toeneboen, B. Wachowicz, R. Willkomm, Submarine lidar for seafloor inspection, Measurement Science and Technology 10 (12) (1999) 1178. doi:10.1088/0957-0233/10/12/309

[6] J. Li, P. R. White, J. M. Bull, T. G. Leighton, A noise impact assessment model for passive acoustic measurements of seabed gas fluxes, Ocean Engineering 183 (1) (2019) 294-304. doi:10.1016/j.oceaneng.2019.03.046

[7] Y. Song, J. Liu, L. Cao, N. Chu, D. Wu, Robust passive underwater acoustic detection method for propeller, Applied Acoustics 148 (2019) 151-161. doi:10.1016/j.apacoust.2018.12.024.

[8] J. Li, Y. V. Zakharov, Efficient use of space-time clustering for underwater acoustic communications, IEEE Journal of Oceanic Engineering 43 (1) (2018) 173-183. doi:10.1109/JOE.2017.2688558

[9] J. Li, Y. V. Zakharov, B. Henson, Multibranch Autocorrelation Method for Doppler Estimation in Underwater Acoustic Channels, IEEE Journal of Oceanic Engineering 43 (4) (2018) 1099 - 1113. doi:10.1109/JOE.2017.2761478

[10] F. Yuan, Z. Jia, J. Li, E. Cheng, STLFM Signal Based Adaptive Synchronization for Underwater Acoustic Communications, IEEE Access 7 (2019) 28734-28748. doi:10.1109/ACCESS.2019.2901357.

11] Y. Zhang, T. Wu, Y. Zakharov, J. Li, MMP-DCD-CV based sparse channel estimation algorithm for underwater acoustic transform domain communication system, Applied Acoustics 154 (2019) 43-52. doi:10.1016/j.apacoust. 2019.04 .019

[12] B. Li, S. Zheng, F. Tong, Bit-error rate based doppler estimation for shallow water acoustic ofdm communication, Ocean Engineering 182 (2019) 203-210. doi:10.1016/j.oceaneng.2019.04.045

[13] J. Li, L. Liao, Y. V. Zakharov, Space-time cluster combining for UWA communications, in: OCEANS 2016-Shanghai, IEEE, 2016, pp. 1-6. doi:10.1109/0CEANSAP.2016.7485344

[14] J. Li, DOA tracking in time-varying underwater acoustic communication channels, in: OCEANS 2017-Aberdeen, IEEE, 2017, pp. 1-9. doi:10.1109/0CEANSE. 2017.8084563

[15] P. T. Arveson, D. J. Vendittis, Radiated noise characteristics of a modern cargo ship, J. Acoust. Soc. Am. 107 (1) (2000) 118-129. doi:10.1121/1.428344

[16] J. A. Shooter, T. E. DeMary, A. F. Wittenborn, Depth dependence of noise resulting from ship traffic and wind, IEEE Journal of Oceanic Engineering 15 (4) (1990) 292-298. doi:10.1109/48.103524.

[17] M. F. McKenna, D. Ross, S. M. Wiggins, J. A. Hildebrand, Underwater radiated noise from modern commercial ships, J. Acoust. Soc. Am. 131 (1) (2012) 92-103. doi:10.1121/1.3664100

[18] N. D. Merchant, E. Pirotta, T. R. Barton, P. M. Thompson, Monitoring ship noise to assess the impact of coastal developments on marine mammals, Marine Pollution Bulletin 78 (1-2) (2014) 85-95. doi:10.1016/j.marpolbul.2013. 10.058

[19] H. B. Blair, N. D. Merchant, A. S. Friedlaender, D. N. Wiley, S. E. Parks, Evidence for ship noise impacts on humpback whale foraging behaviour, Biology letters 12 (8) (2016) 20160005. doi:10.1098/rsbl.2016.0005

[20] S. D. Simpson, J. Purser, A. N. Radford, Anthropogenic noise compromises antipredator behaviour in european eels, Global change biology 21 (2) (2015) 586-593. doi:10.1111/gcb.12685.

[21] Y. Simard, N. Roy, C. Gervaise, S. Giard, Analysis and modeling of 255 source levels of merchant ships from an acoustic observatory along st. lawrence seaway, J. Acoust. Soc. Am. 140 (3) (2016) 2002-2018. doi:10.1121/1.4962557

[22] P. Zhou, H. Wang, Carbon capture and storagesolidification and storage of carbon dioxide captured on ships, Ocean Engineering 91 (2014) 172-180. doi:10.1016/j.oceaneng.2014.09.006

[23] B. Windén, M. Chen, N. Okamoto, D. K. Kim, E. McCaig, A. Shenoi, P. Wilson, Investigation of offshore thermal power plant with carbon capture as an alternative to carbon dioxide transport, Ocean Engineering 76 (2014) $152-162$. doi:10.1016/j.oceaneng.2013.07.016

[24] J. Blackford, N. Jones, R. Proctor, J. Holt, S. Widdicombe, D. Lowe, A. Rees, An initial assessment of the potential environmental impact of CO2 escape from marine carbon capture and storage systems, Proceedings of the Institution of Mechanical Engineers, Part A: Journal of Power and Energy 223 (3) (2009) 269-280. doi:10.1243/09576509JPE623

[25] G. M. Wenz, Acoustic ambient noise in the ocean: spectra and sources, J. Acoust. Soc. Am. 34 (12) (1962) 1936-1956. doi:10.1121/1.1909155

[26] R. K. Andrew, B. M. Howe, J. A. Mercer, Long-time trends in ship traffic noise for four sites off the north american west coast, J. Acoust. Soc. Am. 129 (2) (2011) 642-651. doi:10.1121/1.3518770.

[27] C. Chi, Z. Li, Q. Li, Design of optimal multiple phase-coded signals for broadband acoustical doppler current profiler, IEEE Journal of Oceanic Engineering 41 (2) (2015) 302-317. doi:10.1109/JOE.2015.2442677 
[28] B. Zhang, Y. Xiang, P. He, G.-j. Zhang, Study on prediction methods and characteristics of ship underwater radiated noise within full frequency, Ocean Engineering 174 (2019) 61-70. doi:10.1016/j.oceaneng.2019.01.028

[29] D. Borelli, T. Gaggero, E. Rizzuto, C. Schenone, Analysis of noise on board a ship during navigation and manoeuvres, Ocean Engineering 105 (2015) 256-269. doi:10.1016/j.oceaneng.2015.06.040

[30] G. M. Wenz, Review of underwater acoustics research: Noise, J. Acoust. Soc. Am. 51 (3B) (1972) 1010-1024. doi: 10.1121/1.1912921

31] D. Ross, Ship sources of ambient noise, IEEE Journal of Oceanic Engineering 30 (2) (2005) 257-261. doi:10.1109/ JOE. 2005.850879

[32] F. Traverso, T. Gaggero, G. Tani, M. Viviani, D. Villa, S. Gaggero, E. Rizzuto, A. Trucco, STATISTICAL ANALYSIS OF SHIP NOISE RECORDS, in: The 23rd International Congress on Sound and Vibration, Athens, Greece, International Institute of Acoustics and Vibrations, 2016, pp. 1-6.

[33] S. C. Wales, R. M. Heitmeyer, An ensemble source spectra model for merchant ship-radiated noise, J. Acoust. Soc. Am. 111 (3) (2002) 1211-1231. doi:10.1121/1.1427355

34] G. Grelowska, E. Kozaczka, S. Kozaczka, W. Szymczak, Underwater noise generated by a small ship in the shallow sea, Archives of Acoustics 38 (3) (2013) 351-356. doi:10.2478/aoa-2013-0041

[35] P. Shaw, D. R. Watts, H. T. Rossby, On the estimation of oceanic wind speed and stress from ambient noise measurements, Deep Sea Research 25 (12) (1978) 1225-1233. doi:10.1016/0146-6291(78)90015-2

[36] A. Burgess, D. Kewley, Wind-generated surface noise source levels in deep water east of australia, J. Acoust. Soc. Am. 73 (1) (1983) 201-210. doi:10.1121/1.388840

[37] R. Hamson, The modelling of ambient noise due to shipping and wind sources in complex environments, Applied Acoustics 51 (3) (1997) 251-287. doi:10.1016/S0003-682X(97)00003-0

[38] P. Kellett, O. Turan, A. Incecik, A study of numerical ship underwater noise prediction, Ocean Engineering 66 (2013) 113-120. doi:10.1016/j.oceaneng.2013.04.006

[39] S. Veirs, V. Veirs, Vessel noise measurements underwater in the Haro Strait, WA, J. Acoust. Soc. Am. 120 (5) (2006) 3382-3382. doi:10.1121/1.4781642

40] R. J. Urick, Ambient noise in the sea, Tech. rep., Catholic Univ of America Wshington D.C. (1984). doi:10.1121/1. 398683.

41] C. Piggott, Ambient sea noise at low frequencies in shallow water of the scotian shelf, J. Acoust. Soc. Am. 36 (11) (1964) 2152-2163. doi:10.1121/1.1919337

[42] C. Gervaise, Y. Simard, N. Roy, B. Kinda, N. Menard, Shipping noise in whale habitat: Characteristics, sources, budget, and impact on belugas in Saguenay-St. Lawrence Marine Park hub, J. Acoust. Soc. Am. 132 (1) (2012) 76-89. doi:10.1121/1.4728190

43] G. B. Kinda, F. Le Courtois, Y. Stéphan, Ambient noise dynamics in a heavy shipping area, Marine pollution bulletin 124 (1) (2017) 535-546. doi:10.1016/j.marpolbul.2017.07.031

[44] A. O. MacGillivray, Z. Li, Reductions in underwater radiated noise from shipping during the 2017 haro strait vessel slowdown trial, J. Acoust. Soc. Am. 144 (3) (2018) 1731-1731. doi:10.1121/1.5067678

[45] D. E. Hannay, H. Frouin-Mouy, Z. Li, A. O. MacGillivray, Ranking vessel noise emissions using measurements from an underwater listening station, J. Acoust. Soc. Am. 144 (3) (2018) 1956-1957. doi:10.1121/1.5068553.

[46] N. D. Merchant, P. Blondel, D. T. Dakin, J. Dorocicz, Averaging underwater noise levels for environmental assessment of shipping, J. Acoust. Soc. Am. 132 (4) (2012) EL343-EL349. doi:10.1121/1.4754429

[47] B. Veritas, Underwater Radiated Noise (URN), Rule Note NR 614 DT R00 E, Bureau Veritas.

[48] R. D. Gaul, D. P. Knobles, J. A. Shooter, A. F. Wittenborn, Ambient noise analysis of deep-ocean measurements in the northeast pacific, IEEE Journal of Oceanic Engineering 32 (2) (2007) 497-512. doi:10.1109/JOE.2007.891885.

[49] D. K. Wittekind, A simple model for the underwater noise source level of ships, Journal of Ship production and design 30 (1) (2014) 7-14. doi:10.5957/JSPD.30.1.120052

[50] D. Wittekind, M. Schuster, Propeller cavitation noise and background noise in the sea, Ocean Engineering 120 (2016) 116-121. doi:10.1016/j.oceaneng.2015.12.060.

[51] L. Qi, Y. Wu, M. Zou, Y. Yu, Propeller-shaft-hull coupled vibration and its impact on acoustic radiation utilizing sono-elasticity theory, Ocean Engineering 171 (2019) 391-398. doi:10.1016/j.oceaneng.2018.11.031

[52] M. Zou, Y. Wu, S. Liu, A three-dimensional sono-elastic method of ships in finite depth water with experimental validation, Ocean Engineering 164 (2018) 238-247. doi:10.1016/j.oceaneng.2018.06.052

[53] A. J. Perrone, Deep-Ocean Ambient-Noise Spectra in the Northwest Atlantic, J. Acoust. Soc. Am. 46 (3B) (1969) 762-770. doi:10.1121/1.1911759

[54] D. L. Evans, D. R. Watts, D. Halpern, S. Bourassa, Oceanic winds measured from the seafloor, Journal of Geophysical Research: Oceans 89 (C3) (1984) 3457-3461. doi:10.1029/JC089iC03p03457

55] J. A. Nystuen, Listening to raindrops from underwater: An acoustic disdrometer, Journal of Atmospheric and Oceanic Technology 18 (10) (2001) 1640-1657. doi:10.1175/1520-0426(2001) 018<1640:LTRFUA>2.0.C0;2

[56] A. Chadwick, Review confirms Goldeneye storage capability and capacity Tech. Rep. 1, British Geological Survey (2015). URL https://www.bgs.ac.uk/news/docs/Goldeneye_CO2_storage_Press_Release.pdf

[57] Ship specifications RRS James Cook, Tech. Rep. 1, Natural Environment Research Council (2006). URL https://nerc.ukri.org/research/sites/facilities/marine/ships/jamescook-info-spec/

[58] $89.2 \mathrm{~m}$ Oceanographic Research Vessel for owner NERC, U.K. Tech. rep. (2006). URL https: //www.skipsteknisk.no/product_sheet . aspx?type=4\&menu=29\&id=68

[59] M. B. Porter, The bellhop manual and users guide: Preliminary draft, Heat, Light, and Sound Research, Inc., La Jolla, CA, USA, Tech. Rep.

[60] B. Henson, J. Li, Y. V. Zakharov, C. Liu, Waymark baseband underwater acoustic propagation model, in: 2014 Underwater Communications and Networking (UComms), IEEE, 2014, pp. 1-5. doi:10.1109/UComms.2014.7017132

[61] M. Bahtiarian, ASA standard goes underwater, Acoust. Today 5 (4) (2009) 26-29.

[62] J. Antoni, The spectral kurtosis: a useful tool for characterising non-stationary signals, Mechanical Systems and Signal Processing 20 (2) (2006) 282-307. doi:10.1016/j.ymssp.2004.09.001. 
[63] P. Breuer, P. Major, Central limit theorems for non-linear functionals of gaussian fields, Journal of Multivariate Analysis 13 (3) (1983) 425-441. doi:10.1016/0047-259X (83)90019-2

[64] R. J. Webster, A random number generator for ocean noise statistics, IEEE Journal of Oceanic Engineering 19 (1) (1994) 134-137. doi:10.1109/48.289459

[65] J. Koziol, An alternative formulation of neymans smooth goodness of fit tests under composite alternatives, Metrika 34 (1) (1987) 17-24.

[66] M. Bogdan, Data driven smooth tests for bivariate normality, Journal of Multivariate Analysis 68 (1) (1999) $26-53$. doi:10.1006/jmva.1998.1779.

[67] W. S. Cleveland, S. J. Devlin, Locally weighted regression: an approach to regression analysis by local fitting, Journal of the American statistical association 83 (403) (1988) 596-610. doi:10.1080/01621459.1988.10478639

[68] J. Benesty, J. Chen, Y. Huang, I. Cohen, Pearson correlation coefficient, in: Noise reduction in speech processing, Springer, 2009, pp. 1-4.

[69] P. Welch, The use of fast fourier transform for the estimation of power spectra: a method based on time averaging over short, modified periodograms, IEEE Transactions on audio and electroacoustics 15 (2) (1967) 70-73. doi: 10.1109/TAU.1967.1161901

[70] D. Ross, Mechanics of underwater noise, Elsevier, 2013. doi:10.1121/1.398685

71] B. Aktas, M. Atlar, S. Turkmen, W. Shi, R. Sampson, E. Korkut, P. Fitzsimmons, Propeller cavitation noise investigations of a research vessel using medium size cavitation tunnel tests and full-scale trials, Ocean Engineering 120 (2016) 122-135. doi:10.1016/j.oceaneng.2015.12.040

[72] R. J. Urick, Principles of underwater sound 3rd edition, Peninsula Publising Los Atlos, California.

[73] E. R. Gerstein, Manatees, bioacoustics and boats: hearing tests, environmental measurements and acoustic phenomena may together explain why boats and animals collide, American Scientist 90 (2) (2002) 154-163. 